\title{
Genome-Wide Association Analyses on Blood Pressure Using Three Different Phenotype Definitions
}

\author{
Ji Wan Park ${ }^{1 *}$, Saanyong Uhmm², Chol Shin ${ }^{3}$, \\ Nam H. Cho ${ }^{4}$, Yoon Shin $\mathrm{Cho}^{5}$ and Jong-Young \\ Lee $^{5}$
}

${ }^{1}$ Department of Medical Genetics, College of Medicine and ${ }^{2}$ Department of Computer Engineering, College of Information and Electronic Engineering, Hallym University, Chunchon 200-702, Korea, ${ }^{3}$ Division of Pulmonary and Critical Care Medicine, Department of Internal Medicine, Korea University Ansan Hospital, Ansan 425-707, Korea, ${ }^{4}$ Department of Preventive Medicine, Ajou University School of Medicine, Suwon 442-749, Korea, ${ }^{5}$ Center for Genome Science, National Institute for Health, Seoul 122-701, Korea

\begin{abstract}
Hypertension is the most prevalent disease worldwide and is itself a risk factor for cerebral, cardiac, and renal diseases. The inconsistency of candidate genes suggested by previous genomewide association studies (GWASs) may be due to not only differences in study design and genetic or environmental background but also the difference in the power of analysis between continuous traits and discrete traits. We analyzed 352,228 single nucleotide polymorphisms (SNPs) in 8842 unrelated Koreans obtained from Ansan and Ansung cohorts. We performed a series of GWA analyses using three different phenotype models; young hypertensive cases (278 subjects) versus elderly normotensive controls (680 subjects); the upper $25 \%$ (2211 hypertensive cases) versus the lower $25 \%$ of the SBP distribution (2211 hypotensive controls); and finally SBP and DBP as continuous traits (8842 subjects). The numbers of young hypertensive cases and elderly normotensive controls were not large enough to achieve genomewide significance. The model comparing the upper $25 \%$ subjects to the lower $25 \%$ of subjects showed a power that was approximate to that of QTL analysis. Two neighboring SNPs of the ATP2B1 gene, rs17249754 (SBP, $\mathrm{p}=$ $2.53^{-10}$; DBP, $p=1.28 \times 10^{-8}$ ) and rs7136259 (SBP, $p=$ $1.30 \times 10^{-9}$; DBP, $\mathrm{p}=6.41 \times 10^{-8}$ ), were associated with both SBP and DBP. Interestingly, a SNP of the RPL6 gene, rs11066280, revealed a significant genomewide
\end{abstract}

*Corresponding author: E-mail jwpark@hallym.ac.kr Tel +82-33-248-2691, Fax +82-33-248-2696 Accepted 24 August 2010 association with SBP in men only $\left(\mathrm{p}=3.85 \times 10^{-8}\right)$, and four SNPs located near the MAN2A1 gene showed a strong association with DBP only in elderly men aged 60-70 years (e.g., rs6421827, $\mathrm{p}=4.86 \times 10^{-8}$ ). However, we did not observe any gene variant attaining genomewide significance consistently in the three phenotype models except for the ATP2B1 gene variants. In general, the association signal with blood pressure was stronger in women than in men. Genes identified in GWASs are expected to open the way for prevention, early diagnosis, and personalized treatment of hypertension.

Keywords: genomewide association study, blood pressure, case-control study, continuous trait locus analysis, single nucleotide polymorphism

\section{Introduction}

Nearly one billion people $(-26 \%)$ of the adult population worldwide have hypertension (Kearney et al. 2005). According to the Korean National Health and Nutrition Examination Survey (KNHANES 2008, http://knhanes, cdc.go.kr/), the prevalence of hypertension is $26.9 \%$ among Korean adults aged above 30 years. Clinically, the diagnosis of hypertension is given when the systolic blood pressure (SBP) and diastolic blood pressure (DB) are above $140 / 90 \mathrm{~mm} \mathrm{Hg}$ in the resting position. About $90 \%$ to $95 \%$ of cases are primary (essential) hypertension, which refers to high blood pressure that is not caused by any other disorders (Carretero and Oparil, 2000).

Hypertension is one of risk factors for cerebral, cardiac, and renal diseases (Pierdomenico et al., 2009). On the other hand, essential hypertension usually occurs with cardiovascular risk factors, such as aging, obesity, type 2 diabetes (T2DM), and hormone disorders. Lifestyle factors that are known to cause hypertension include sedentary lifestyle, high stress, high salt intake, and alcohol consumption (Kyrou et al., 2006). Both blood pressure and hypertension are traditional examples of complex traits controlled by the complex interplay of genes and environmental factors (Pickering et al., 1959). The heritability of blood pressure ranges from $31 \%$ to $68 \%$, depending on studies based on different measurements of SBP and DBP (Pilia et al., 2006; Tobin et al., 2005).

Ehret (2010) summarized the 12 genomewide association studies (GWASs) on blood pressure and hyper- 
tension that were recently published. While 10-20 loci were identified in previous GWASs, only two (i.e. CYP17A1, MTHFR) genes were reproducibly associated with blood pressure or essential hypertension in large cohorts. Ehret (2010) pointed out the possibility that the differences in significant SNPs that were identified among these 12 GWASs may be due to the difference in power of analysis between continuous traits and discrete traits. A continuous trait provides more variation than a discrete trait; thus, continuous trait locus (QTL) analysis is considered to be more powerful than discrete trait analysis (e.g., case-control analysis) (Potkin et al., 2009). However, means of SBPs and DBPs measured in a general population (i.e., a cohort) may not be representative of the true means in the population, since most hypertensive patients have taken antihypertensive drugs to lower their blood pressure. On the other hand, comparing extreme discordant phenotypes, such as individuals at the lowest end versus individuals at the highest end of the blood pressure spectrum, may be a powerful approach in GWASs (Nebert, 2000).

In this study, we have compared the gene variants associated with quantitative blood pressures (SBP and DBP) with those identified in GWASs using different definitions of discrete phenotypes to present an alternative strategy that has increased statistical power over a case-control study in the context of a GWAS for hypertension.

\section{Methods}

\section{Study samples and genotype data}

The study subjects were obtained from the two community cohorts, Ansung and Ansan, which were established in a rural area and an urban, respectively, in South Korea, as part of the Korean Genome Epidemiology Study (KoGES), launched in 2001. The Korea
Association Resource (KARE) project was initiated in 2007 , and a total of 10,038 unrelated Koreans were genotyped with the Affymetrix Genomewide Human SNP array 5.0 (Affymetrix Inc., Santa Clara, CA, USA). After exclusion of inadequate samples with high genotype missing rate, high heterozygosity, gender inconsistencies, cancer, and high identity-by-state $(>0.8)$, a total of 8842 individuals aged 40 to 69 years were included in the subsequent analyses. We analyzed 352,228 single nucleotide polymorphism (SNP) markers after excluding $29.6 \%$ of the $500 \mathrm{~K}$ SNPs with low genotype quality (i.e., missing call rate $>5 \%$, minor allele frequency (MAF) $<$ $1 \%$, and Hardy-Weinberg Equilibrium (HWE) $p<1 \times 10^{-6}$ ). Further details can be found elsewhere (Choi et al. 2009), and the characteristics of the 8842 individuals are summarized in Table 1.

\section{Statistical analysis}

We calculated the mean and standard deviation (SD) for the continuous variables and counted the number and frequencies for discrete variables by gender to describe the baseline characteristics of study subjects using the STATA software package, v11 (Stata Corp, College station, Texas, USA). We drew box plots of systolic (SBP) and diastolic blood pressure (DBP) by gender and three age groups (39-49, 50-59, and 60-70) using R program, v2.9.1 (http://www,r-project.org).

Three phenotype models were used: first, we compared the younger age group of 39-49 years with high SBP ( $\geq 140 \mathrm{~mm} \mathrm{Hg}$ ) and the elderly age group of 60-70 years with low SBP ( $<120 \mathrm{~mm} \mathrm{Hg}$ ); second, we performed a GWAS by comparing the upper $25 \%$ and lower $25 \%$ of the SBP distribution; and finally, we performed QTL analyses on SBP and DBP. We used PLINK v1.06 to estimate MAF, to test for deviations from HWE, and to conduct single-marker genomewide association tests (Purcell et al., 2007). While we tested discrete phe-

Table 1. Baseline characteristics of the study subjects

\begin{tabular}{lccc}
\hline \multicolumn{1}{c}{ Variables } & Men & Women & Total \\
\hline Sex, $\mathrm{N} \mathrm{( \% )}$ & $4,183(47.31)$ & $4,659(52.69)$ & $8,842(100)$ \\
Age, years $\pm \mathrm{SD}^{\mathrm{a}}$ & $51.78 \pm 8.79$ & $52.61 \pm 9.02$ & $52.22 \pm 8.92$ \\
Living in Ansan & $2,374(56.75)$ & $2,263(48.57)$ & $4,636(52.44)$ \\
Ansung, $\mathrm{N}(\%)$ & $1,809(43.25)$ & $2,396(51.43)$ & $4,205(47.56)$ \\
Body mass index, $\mathrm{kg} / \mathrm{m}^{2}$ & $24.25 \pm 2.93$ & $24.91 \pm 3.26$ & $24.60 \pm 3.12$ \\
Systolic blood pressure, mm Hg & $122.25 \pm 17.36$ & $121.12 \pm 19.64$ & $121.65 \pm 18.61$ \\
Diastolic blood pressure, mm Hg & $81.83 \pm 10.94$ & $78.86 \pm 11.74$ & $80.26 \pm 11.46$ \\
Hypertension medication ${ }^{\mathrm{b}}, \mathrm{no}$ & $3,541(89.67)$ & $3,746(85.25)$ & $7,287(87.34)$ \\
Yes, N (\%) & $408(10.33)$ & $648(14.75)$ & $1,056(12.66)$ \\
\hline
\end{tabular}

${ }^{\mathrm{a}} \mathrm{SD}$ represents the standard deviation of the mean of each trait, ${ }^{\mathrm{b}}$ The numbers did not include 499 subjects with missing data regarding hypertension medication use. 
notypes in multiple logistic regression analyses, we carried out multiple linear regression analyses between 352,228 SNP markers with SBP and DBP using models with adjustments for age, sex, place of residence, and $\mathrm{BMI}$ under an additive genetic model. Further analyses were performed after stratification of gender with adjustments for age, place of residence, and BMI. We summarized the GWAS results with the integration of PLINK output and annotation data using Python v2.6.2 (http:// python.org). We present the Manhattan plots of the GWAS results, which were drawn using R v.2.9.1.

\section{Results}

As shown in Table 1, the study subjects were composed of 4183 men (47.3\%) and 4659 women (52.7\%) with a mean age of 52 and 53 years, respectively. Among 7287 individuals who answered the question on medication use, $10.3 \%$ of men and $14.8 \%$ of women answered that they had taken antihypertensive drugs. The mean SBP and mean DBP among men (122/82 mm $\mathrm{Hg}$ ) were slightly higher than those of women $(121 / 79$ $\mathrm{mm} \mathrm{Hg}$ ).

The box plots present the distributions of SBP and DBP by gender and age (Fig. 1). Blood pressure tended to increase with age, especially in the case of SBP. The upper $25 \%$ and lower $25 \%$ of the SBP distribution in men, women, and all subjects were 110/132, 107/133, and $109 / 132 \mathrm{~mm} \mathrm{Hg}$, respectively. The corresponding values of DBP were 74/89, 70/87, and 72/88 mm Hg, respectively. While the distribution of DBP was approximately normal, the distribution of SBP was slightly
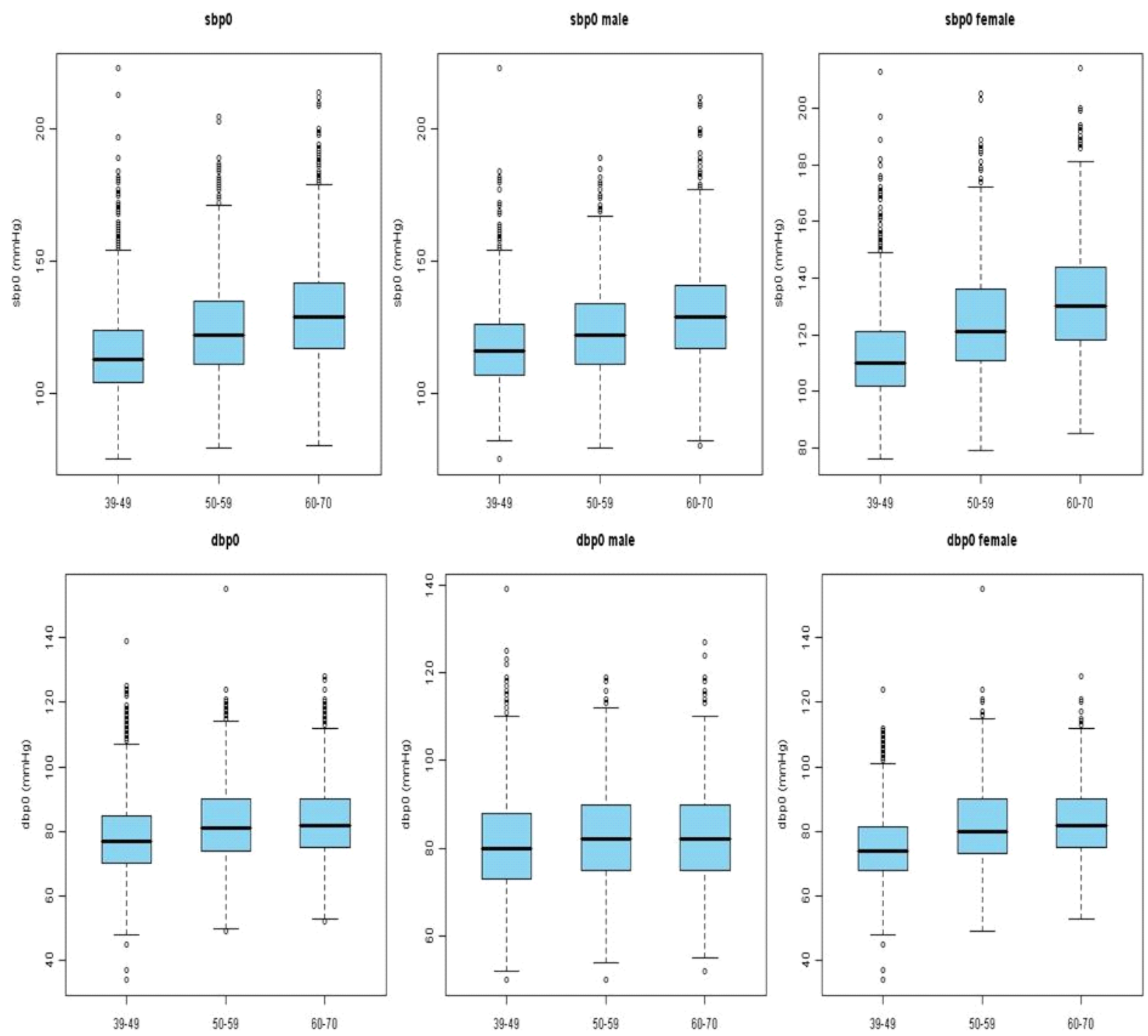

Fig. 1. Box plots of systolic (SBP) and diastolic blood pressure (DBP) by sex and age. 
$39-49,>=140 \mathrm{mmHg}$ vs. $60-70,<120 \mathrm{mmHg}$
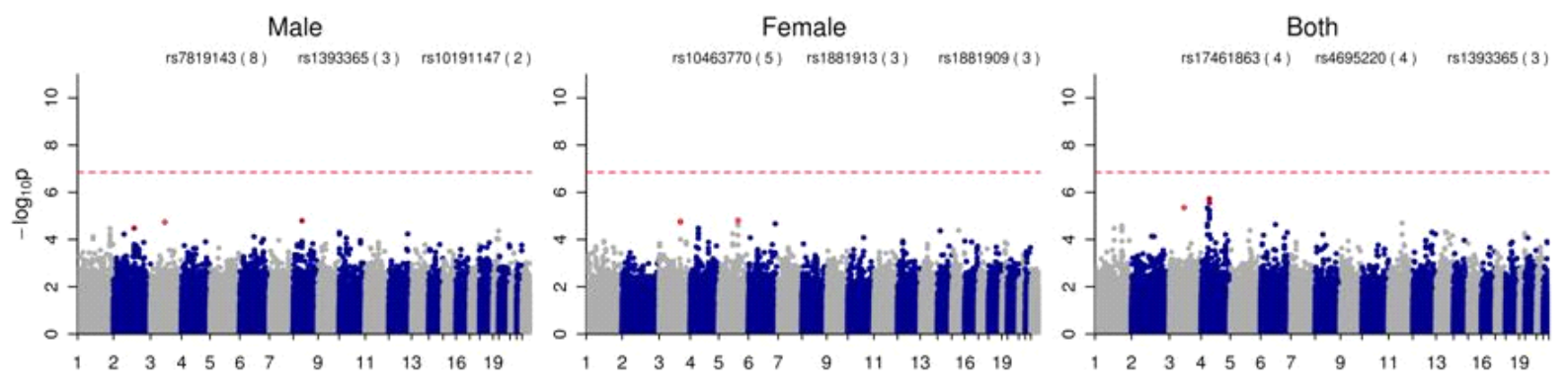

High $25 \%$ vs. Low $25 \%$
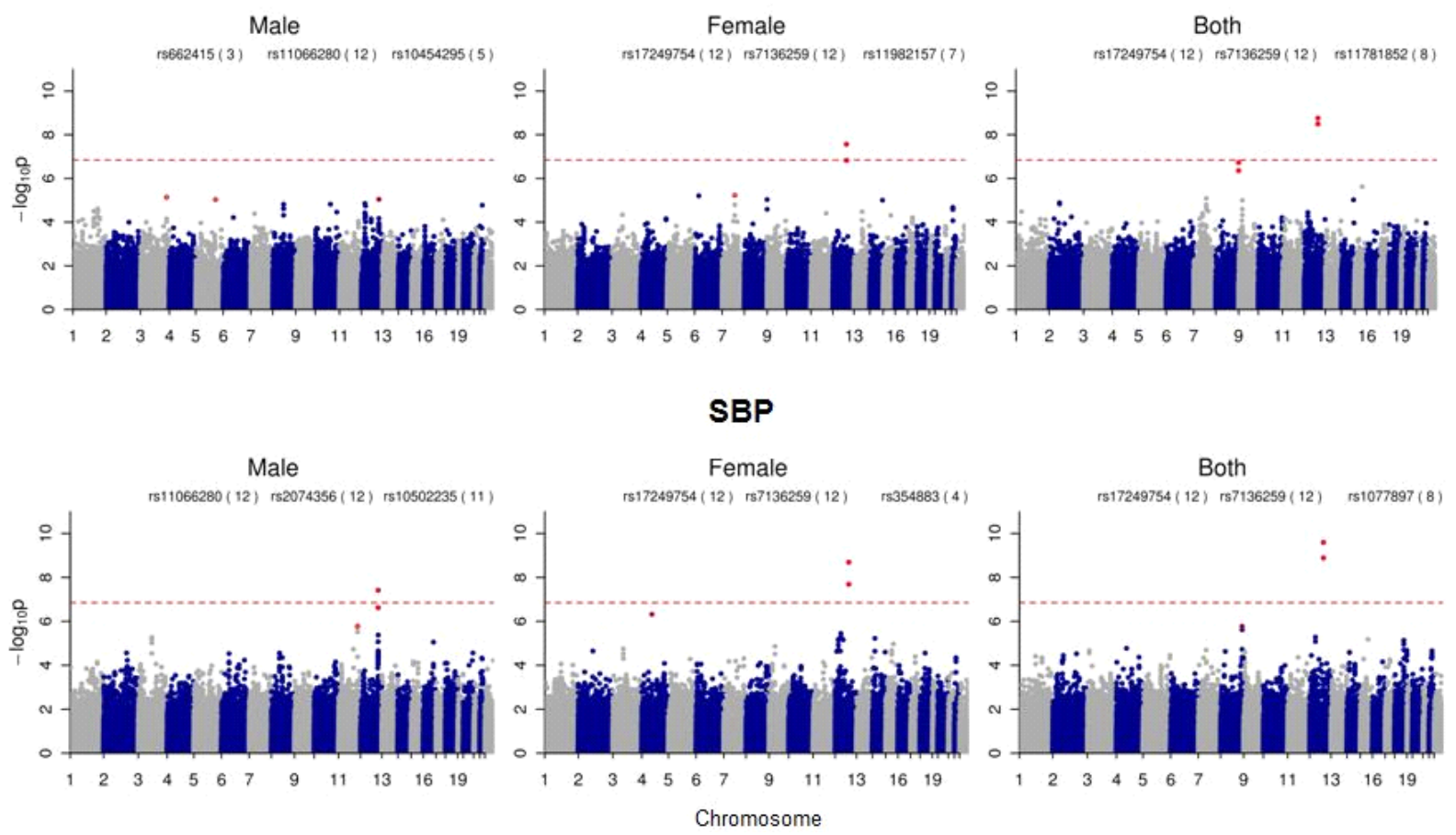

Fig. 2. Manhattan plots of GWASs using three different phenotype definitions of systolic blood pressure (SBP).

skewed to the right. Since most previous GWASs on SBP were conducted without any transformation, we performed a GWAS using the untransformed SBP response variable for comparability with the previous reports.

Initially, we compared the GWAS results obtained by using three different phenotype definitions for SBP (Table 2). Although we compared comparably young hypertensive cases (SBP $\geq 140 \mathrm{~mm} \mathrm{Hg}$ ) with elderly normotensive controls (SBP $<120 \mathrm{~mm} \mathrm{Hg}$ ) to increase the statistical power, the numbers of cases and controls were not sufficiently large enough to achieve a genomewide level of significance. Fig. 2 shows two SNPs that exceeded the genomewide threshold in the QTL analysis as well as in the discrete trait analysis, comparing the upper $25 \%$ of individuals with hypertension with the lower $25 \%$ of individuals with hypotension. As expected, the strongest evidence for association was observed in the QTL analysis, due to not only the higher power of the QTL analysis over discrete analysis but also the largest pool of subjects being analyzed in this QTL analysis. While the estimate of the effect of this SNP was in the same direction for both genders, the association signal was stronger in women than in men.

In Table 3, we show the candidate genes corresponding to the top 9 SNPs identified from the three GWAS models using different definitions for SBP. Two SNPs, rs17249754 and rs7136259, located approximately 10 $\mathrm{kb}$ and $31 \mathrm{~kb}$ from the $5^{\prime}$ end of the ATPase, Ca++ transporting, plasma membrane 1 (ATP2B1) gene, passed 
Table 2. Comparison of numbers of SNPs showing significant evidence for association with SBP in GWASs using three different phenotype definitions

\begin{tabular}{lrrrrrrrrr}
\hline \multicolumn{1}{c}{ Phenotype $^{\mathrm{a}}$} & \multicolumn{3}{c}{ Case Control } & \multicolumn{1}{c}{$25 \%$ High vs. $25 \%$ Low } & \multicolumn{3}{c}{ SBP } \\
\cline { 2 - 10 } Sex & \multicolumn{1}{c}{$\mathrm{M}$} & $\mathrm{F}$ & $\mathrm{T}$ & $\mathrm{M}$ & $\mathrm{F}$ & $\mathrm{T}$ & $\mathrm{M}$ & $\mathrm{F}$ & $\mathrm{T}$ \\
Cases & 157 & 121 & 278 & 1,046 & 1,165 & 2,211 & 4,183 & 4,659 & 8,842 \\
Controls & 303 & 377 & 680 & 1,046 & 1,165 & 2,211 & & & \\
\hline $\mathrm{p}<0.05$ & 18412 & 17462 & 18177 & 18641 & 18344 & 19147 & 18651 & 18897 & 19549 \\
$\mathrm{p}<10^{-3}$ & 322 & 277 & 352 & 364 & 348 & 423 & 453 & 416 & 504 \\
$\mathrm{p}<10^{-5}$ & 0 & 0 & 7 & 3 & 6 & 7 & 12 & 9 & 9 \\
$\mathrm{p}<10^{-7}$ & 0 & 0 & 0 & 0 & 1 & 2 & 1 & 2 & 2 \\
FDR $\mathrm{p}<0.05^{\mathrm{c}}$ & 0 & 0 & 0 & 0 & 2 & 4 & 2 & 2 & 2 \\
Bonf $\mathrm{p}<0.05^{\mathrm{c}}$ & 0 & 0 & 0 & 0 & 1 & 2 & 1 & 2 & 2 \\
\hline
\end{tabular}

${ }^{a}$ Cases were defined as the younger age group (39-49 years) with high SBP ( $\geq 140 \mathrm{~mm} \mathrm{Hg}$ ), and controls were the elderly age group (60-70 years) with low SBP ( $<120 \mathrm{~mm} \mathrm{Hg}$ ); the GWAS results,comparing the upper $25 \%$ to the lower $25 \%$ of the SBP distributions; QTL analyses on SBP, ${ }^{b} \mathrm{M}$, men; F, women; $\mathrm{T}$, both genders combined, ${ }^{\mathrm{c}} \mathrm{FDR}$, false discovery rate; Bonf $\mathrm{p}<0.05$, Bonferroni-corrected significance level of $\mathrm{p}<0.05$.

Table 3. Comparison of genetic variants associated with SBP in the genomewide association analyses using three different phenotype definitions

\begin{tabular}{|c|c|c|c|c|c|c|c|c|c|c|c|}
\hline \multicolumn{4}{|c|}{ Case control } & \multicolumn{4}{|c|}{$25 \%$ High vs. $25 \%$ Low } & \multicolumn{4}{|c|}{ SBP } \\
\hline SNP & Gene & $\mathrm{Chr}^{\mathrm{a}}$ & $p$ & SNP & Gene & Chr. & $p$ & SNP & Gene & Chr. & $p$ \\
\hline rs $17461863^{*{ }^{\circ}}$ & GABRB1 & $4 \mathrm{p} 12$ & $1.8910^{-6}$ & rs17249754 & ATP2B1 & $12 q 21.33$ & $1.7410^{-9}$ & rs17249754 & ATP2B1 & $12 q 21.33$ & $2.5310^{-10}$ \\
\hline rs4695220* & GABRB1 & $4 \mathrm{p} 12$ & $2.8110^{-6}$ & rs7136259 & ATP2B1 & $12 q 21.33$ & $3.1910^{-9}$ & rs7136259 & ATP2B1 & $12 q 21.33$ & $1.3010^{-9}$ \\
\hline rs1393365 & $R O B O 1$ & $3 p 12.3$ & $4.4610^{-6}$ & rs11781852 & $G M L$ & $8 q 24.3$ & $1.8810^{-7}$ & rs1077897 & KHDRBS3 & $8 q 24.23$ & $1.6710^{-6}$ \\
\hline rs16990689 & ARAP1 & $4 \mathrm{p} 15.1$ & $4.7110^{-6}$ & rs $3764795^{\star \star}$ & $G M L$ & $8 q 24.3$ & $4.3810^{-7}$ & rs6578241 & KHDRBS3 & $8 q 24.23$ & $2.4110^{-6}$ \\
\hline rs11733050* & $G A B R B 1$ & $4 \mathrm{p} 12$ & $5.8610^{-6}$ & rs1378942* & $S R C$ & $15 q 24.1$ & $2.3910^{-6}$ & rs16918920 & $\mathrm{H} 3 \mathrm{~F} 3 \mathrm{C}$ & $12 \mathrm{p} 11.21$ & $5.2510^{-6}$ \\
\hline rs7677890* & GABRB1 & $4 \mathrm{p} 12$ & $6.0810^{-6}$ & rs11982157 & $R P L 7 P 30$ & $7 q 21.11$ & $8.1510^{-6}$ & rs $1378942^{*}$ & $S R C$ & $15 q 24.1$ & $6.6510^{-6}$ \\
\hline rs10517184* & GABRB1 & $4 \mathrm{p} 12$ & $8.8210^{-6}$ & rs8007031 & C14orf64 & $14 q 32.2$ & $9.5810^{-6}$ & rs $1030582^{*}$ & $P I G A$ & $18 q 21.33$ & $7.2810^{-6}$ \\
\hline rs4694846* & GABRB1 & $4 \mathrm{p} 12$ & $1.1810^{-5}$ & rs11125815 & $B C L 11 A$ & $2 \mathrm{p} 16.1$ & $1.3010^{-5}$ & rs12458329* & $P / G A$ & $18 q 21.33$ & $7.5410^{-6}$ \\
\hline rs7928126 & LOC10028 & $11 q 14.1$ & $2.0110^{-5}$ & rs 11125814 & $B C L 11 A$ & $2 \mathrm{p} 16.1$ & $1.4810^{-5}$ & rs11051588 & $\mathrm{H} 3 \mathrm{~F} 3 \mathrm{C}$ & $12 \mathrm{p} 11.21$ & $8.2810^{-6}$ \\
\hline
\end{tabular}

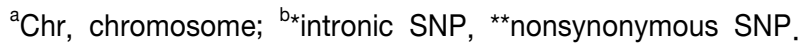

the Bonferroni correction in the model for SBP as a QT and the model-namely, 25\% High versus 25\% Low SBP. However, we did not observe any gene identified consistently in the three GWA analyses, except these two SNPs, which achieved the Bonferroni level of significance. Among the top-ranking SNPs observed in the analysis of young hypertensive cases and elderly normotensive controls, six SNPs were located in the introns of the gamma-aminobutyric acid (GABA) A receptor, beta 1 (GABRB1) gene. In the $25 \%$ High versus $25 \%$ Low SBP GWAS, rs3764795 was located in an exon of glycosylphosphatidylinositol-anchored molecule-like protein (GML, 8q24.3); this SNP is a missense mutation that causes an Arg-to-Cys substitution.

We have provided more detailed information on the three SNPs that passed the Bonferroni correction in the GWAS for SBP and DBP in Table 4. The mean differences and $95 \%$ confidence intervals $(95 \% \mathrm{Cl})$ that were estimated in men, women, and both genders, respectively, are shown in this table. While the two SNPs of the ATP2B1 gene showed a stronger effect in women, rs11066280, which is $25.2 \mathrm{~kb}$ downstream of the ribosomal protein L6 (RPL6) gene, showed a significant genomewide association in men only. The association of ATP2B1 with SBP was stronger than that with DBP. Interestingly, four SNPs that are $92.4 \mathrm{~kb}$ upstream of the mannosidase, alpha, class 2A, member 1 (MAN2A1) gene showed strong evidence for an association with DBP in elderly men only (e.g. rs6421827, $p=4.86 \times 10^{-8}$ ) (data not shown).

\section{Conclusion}

Quantitative phenotype is inherently different from a case-control study. The use of QTs as phenotypes increase the statistical power over categorical association 
Table 4. Genetic variants significantly associated with SBP and DBP (Bonferroni $p<0.05$ )

\begin{tabular}{|c|c|c|c|c|c|c|c|c|c|}
\hline \multirow{2}{*}{$\begin{array}{l}\text { Gene } \\
\text { chr. }\end{array}$} & \multirow{2}{*}{$\begin{array}{c}\text { SNP } \\
\text { location }\end{array}$} & \multirow{2}{*}{$\mathrm{M} / \mathrm{m}$} & \multirow{2}{*}{ Sex } & \multirow{2}{*}{$\mathrm{MM} / \mathrm{Mm} / \mathrm{mm}$} & \multirow{2}{*}{ HWE $p$} & \multirow{2}{*}{ MAF } & SBP & \multicolumn{2}{|l|}{ DBP } \\
\hline & & & & & & & $\beta \quad(95 \% \mathrm{Cl})$ & $\beta \quad(95 \% \mathrm{Cl})$ & $\mathrm{p}$ \\
\hline ATP2B1 & rs17249754 & $\mathrm{G} / \mathrm{A}$ & Men & $1553 / 1885 / 571$ & 1 & 0.38 & $-1.07(-1.79-0.35)$ & $3.50 \times 10^{-3}-0.64(-1.11--0.17)$ & $7.80 \times 10^{-3}$ \\
\hline \multirow[t]{5}{*}{$12 q 21.33$} & $10.7 \mathrm{~kb} \mathrm{5}$ & & Women & $1821 / 2027 / 648$ & 0.03 & 0.37 & $-2.16(-2.86-1.45)$ & $2.03 \times 10^{-9}-1.23(-1.67--0.79)$ & $3.92 \times 10^{-8}$ \\
\hline & & & Both & $3374 / 3912 / 1219$ & 0.12 & 0.37 & $-1.63(-2.13-1.13)$ & $2.53 \times 10^{-10}-0.94(-1.26--0.61)$ & $1.28 \times 10^{-8}$ \\
\hline & rs7136259 & $\mathrm{G} / \mathrm{A}$ & Men & $1548 / 1909 / 602$ & 0.74 & 0.38 & $-1.10(-1.81-0.40)$ & $2.28 \times 10^{-3}-0.63(-1.10--0.17)$ & $7.55 \times 10^{-3}$ \\
\hline & $31.3 \mathrm{~kb} \mathrm{5}$ & & Women & $1761 / 2132 / 667$ & 0.59 & 0.38 & $-2.02(-2.72-1.31)$ & $2.04 \times 10^{-8}-1.16(-1.60--0.72)$ & $2.01 \times 10^{-7}$ \\
\hline & & & Both & $3309 / 4041 / 1269$ & 0.54 & 0.38 & $-1.55(-2.05-1.05)$ & $1.30 \times 10^{-9}-0.88(-1.20--0.56)$ & $6.41 \times 10^{-8}$ \\
\hline RPLG & rs11066280 & $\mathrm{A} / \mathrm{T}$ & Men & $2785 / 1142 / 131$ & 0.30 & 0.17 & $-2.54(-3.44-1.63)$ & $3.85 \times 10^{-8}-1.321(-1.91--0.73)$ & $1.23 \times 10^{-5}$ \\
\hline \multirow[t]{2}{*}{$12 q 24.13$} & $25.2 \mathrm{~kb} \sim 3^{\prime}$ & & Women & $3124 / 1320 / 118$ & 0.13 & 0.17 & $0.10(-0.82-1.03)$ & $8.27 \times 10^{-1}-0.197(-0.77-0.38)$ & $5.00 \times 10^{-1}$ \\
\hline & & & Both & $5909 / 2462 / 249$ & 0.73 & 0.17 & $-1.18(-1.83-0.53)$ & $3.62 \times 10^{-4}-0.749(-1.16--0.33)$ & $4.00 \times 10^{-4}$ \\
\hline
\end{tabular}

approaches in the context of a GWAS of hypertension. In contrast to a case-control analysis, a QT analysis has considerably greater power. A QT analysis can identify the same risk genes found in a typical case-control study or an entirely different set of genes because of the specificity of the phenotype definition.

In this study, we compared the gene variants associated with quantitative blood pressure (SBP and DBP) with those identified in GWASs using different definitions of discrete phenotype. The numbers of young hypertensive cases and elderly normotensive controls were not large enough to achieve genomewide significance. The model comparing the upper $25 \%$ to the lower $25 \%$ of subjects showed a power that was approximate to that of the QTL analysis. Two neighboring SNPs, rs17249754 and rs7136259 of the ATP2B1 gene, were associated with both SBP and DBP. Interestingly, an SNP of the RPL6 gene, rs11066280, revealed a significant genomewide association with SBP in men only, and four SNPs, located near the MAN2A1 gene, showed a strong association with DBP in elderly men aged 60-70 years only. However, we did not observe any gene variant that attained genomewide significance consistently in the three phenotypic models, except for the ATP2B1 gene variants.

So far, 10-20 loci have been proposed as candidate genes for hypertension. However, only two genes reported in previous studies were replicated in the 12 recently published GWASs (Ehret, 2010). Previously, we reported the association of $A T P 2 B 1$ with SBP and DBP using the Korea Association Resource (KARE) data obtained from two Korean community-based populations (Cho et al., 2009). Among the genes reported in previous studies, two genes, SRC (also called CSK, rs1378942, 15q24.1) and ATP2B1 (12q21.33), were also identified in the current study. The association between the $S R C$ gene and DBP was shown in the Global BP Gene Study (Newton-Cheh et al., 2009), and the ATP2B1 gene was associated with SBP and DBP, as well as hypertension, in the CHARGE study (Levy et al.,
2009). ATP2B1 plays a critical role in intracellular calcium homeostasis (Ehret, 2010); thus, it is biologically plausible that the gene variants are involved in blood pressure control.

Previous studies analyzed the KARE data to replicate the association of six SNPs with essential hypertension, reported by the Wellcome Trust GWAS, and to identify nonsynonymous SNPs associated with BP and hypertension through the analysis of 1180 nsSNPs that are included in the Affymerix SNP Array 5.0. A total of 7551 individuals were analyzed after excluding antihypertensive therapy from the SBP and DBP GWAS. Such variables as age, sex, area, and BMI were controlled in their QTL analyses. However, none of the SNPs was replicated in the Korean population at the genomewide significance level in these analyses (Hong et al., 2009; 2010a). Recently, Hong et al, identified 10 SNPs associated with blood pressure and hypertension risk using the KARE data, composed of 8842 individuals, and replicated three SNPs-17249754 of the ATP2B1 gene, rs 1378942 in the CSK gene, and rs12945290 in the ARSG gene-in the Health2 data on 7861 subjects (Hong et al., 2010b).

In the current study, we did not exclude 1056 individuals who had taken antihypertensive drugs. The patients who were currently taking antihypertensive drugs might reduce their $\mathrm{BP}$, and therefore, the strength of association might be diluted and the statistical power might decrease when these individuals are included in the QTL analysis. This means that including individuals who are taking antihypertensive drugs increases the false negative rate instead of increasing the false positive association. It may be a reason for the inconsistency of the results of the current study and those of Hong et al. The GWASs on blood pressure have provided valuable insights into the underlying genetic architecture of essential hypertension. However, much work remains to be done in understanding the functional and pathophysiological properties of the gene variants that were identified in the previous GWASs. Future studies 
on rare variants with intermediate or large effect on BP might facilitate the investigation of heritability of BP. The genes that have been identified in GWASs are expected to open the way for the prevention, early diagnosis, and personalized treatment of hypertension.

\section{Acknowledgments}

This research was performed within the Consortium for Large Scale Genomewide Association Study II (2010E00832-00), which is supported by genotyping data funded by a grant from the Korea Center for Disease Control (the Korean Genome Analysis Project, 4845-301) and by the Hallym University Research Fund, 2010. We thank Min A. Jhun for her assistance with the data analysis.

\section{References}

Carretero, O.A., and Oparil, S. (2000). Essential hypertension. Part I: definition and etiology. Circulation 101, 329-335

Cho, Y.S., Go, M.J., Kim, Y.J., Heo, J.Y., Oh, J.H., Ban, H.J., Yoon, D., Lee, M.H., Kim, D.J., Park, M., Cha, S.H., Kim, J.W., Han, B.G., Min, H., Ahn, Y., Park, M.S., Han, H.R., Jang, H.Y., Cho, E.Y., Lee, J.E., Cho, N.H., Shin, C., Park, T., Park, J.W., Lee, J.K., Cardon, L., Clarke, G., McCarthy, M.I., Lee, J.Y., Oh, B., and Kim, H.L. (2009). A large-scale genome-wide association study of Asian populations uncovers genetic factors influencing eight quantitative traits. Nat. Genet. 41, 527-534.

Ehret, G.B. (2010). Genome-wide association studies: contribution of genomics to understanding blood pressure and essential hypertension. Curr. Hypertens. Rep. 12, 17-25. Review.

Hong, K.W., Jin, H.S., Lim, J.E., Cho, Y.S., Go, M.J., Jung, J., Lee, J.E., Choi, J., Shin, C., Hwang, S.Y., Lee, S.H., Park, H.K., and Oh, B. (2010a). Non-synonymous single-nucleotide polymorphisms associated with blood pressure and hypertension. J. Hum. Hypertens, Feb 11. [Epub ahead of print]

Hong, K.W., Jin, H.S., Lim, J.E., Kim, S., Go, M.J., and Oh, B. (2010b). Recapitulation of two genomewide association studies on blood pressure and essential hypertension in the Korean population. J. Hum. Genet. 55, 336-341.

Hong, K.W., Jin, H.S., Cho, Y.S., Lee, J.Y., Lee, J.E., Cho, N.H., Shin, C., Lee, S.H., Park, H.K., and Oh, B. (2009). Replication of the Wellcome Trust genome-wide association study on essential hypertension in a Korean population. Hypertens, Res, 32,570-574.

Kearney, P.M., Whelton, M., Reynolds, K., Muntner, P., Whelton, P.K., and He, J. (2005). Global burden of hypertension: analysis of worldwide data. Lancet. 365, 217-223.

Kyroul, I., Chrousos, G.P., and Tsigos, C. (2006). Stress, visceral obesity, and metabolic complications. Ann. N.Y. Acad. Sci. 1083, 77-110.
Levy, D., Ehret, G.B., Rice, K., Verwoert, G.C., Launer, L.J., Dehghan, A., Glazer, N.L., Morrison, A.C., Johnson, A.D., Aspelund, T., Aulchenko, Y., Lumley, T., Kottgen, A., Vasan, R.S., Rivadeneira, F., Eiriksdottir, G., Guo, X., Arking, D.E., Mitchell, G.F., Mattace-Raso, F.U.S., Smith, A.V., Taylor, K., Scharpf, R.B., Hwang, S.J., Sijbrands, E.J.G., Bis, J., Harris, T.B., Ganesh, S.K., O'Donnell, C.J., Hofman, A., Rotter, J.I., Coresh, J., Benjamin, E.J., Uitterlinden, A.G., Heiss, G., Fox, C.S., Witteman, J.C.M., Boerwinkle, E., Wang, T.J., Gudnason, V., Larson, M.G., Chakravarti, A., Psaty, B.M., and van Duijn, C.M. (2009). Genome-wide association study of blood pressure and hypertension. Nat. Genet. 41, 677-687.

Nebert, D.W. (2000) Extreme discordant phenotype methodology: an intuitive approach to clinical pharmacogenetics. Eur. J. Pharmacol. 410, 107-120.

Newton-Cheh, C., Johnson, T., Gateva, V., Tobin, M.D., Bochud, M., Coin, L., Najjar, S.S., Zhao, J.H., Heath, S.C., Eyheramendy, S., Papadakis, K., Voight, B.F., Scott, L.J., Zhang, F., Farrall, M., Tanaka, T., Wallace, C., Chambers, J.C., Khaw, K.T., Nilsson, P., van der Harst, P., Polidoro, S., Grobbee, D.E., Onland-Moret, N.C., Bots, M.L., Wain, L.V., Elliott, K.S., Teumer, A., Luan, J., Lucas, G., Kuusisto, J., Burton, P.R., Hadley, D., McArdle, W.L., Wellcome Trust Case Control Consortium, Brown, M., Dominiczak, A., Newhouse, S.J., Samani, N.J., Webster, J., Zeggini, E., Beckmann, J.S., Bergmann, S., Lim, N., Song, K., Vollenweider, P., Waeber, G., Waterworth, D.M., Yuan, X., Groop, L., Orho-Melander, M., Allione, A., Di Gregorio, A., Guarrera, S., Panico, S., Ricceri, F., Romanazzi, V., Sacerdote, C., Vineis, P., Barroso, I., Sandhu, M.S., Luben, R.N., Crawford, G.J., Jousilahti, P., Perola, M., Boehnke, M., Bonnycastle, L.L., Collins, F.S., Jackson, A.U., Mohlke, K.L., Stringham, H.M., Valle, T.T., Willer, C.J., Bergman, R.N., Morken, M.A., Doring, A., Gieger, C., Illig, T., Meitinger, T., Org, E., Pfeufer, A., Wichmann, H.E., Kathiresan, S., Marrugat, J., O'Donnell, C.J., Schwartz, S.M., Siscovick, D.S., Subirana, I., Freimer, N.B., Hartikainen, A.L., McCarthy, M.I., O'Reilly, P.F., Peltonen, L., Pouta, A., de Jong, P.E., Snieder, H., van Gilst, W.H., Clarke, R., Goel, A., Hamsten, A., Peden, J.F., Seedorf, U., Syvanen, A.C., Tognoni, G., Lakatta, E.G., Sanna, S., Scheet, P., Schlessinger, D., Scuteri, A., Dorr, M., Ernst, F., Felix, S.B., Homuth, G., Lorbeer, R., Reffelmann, T., Rettig, R., Volker, U., Galan, P., Gut, I.G., Hercberg, S., Lathrop, G.M., Zelenika, D., Deloukas, P., Soranzo, N., Williams, F.M., Zhai, G., Salomaa, V., Laakso, M., Elosua,

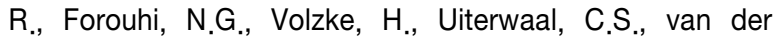
Schouw, Y.T., Numans, M.E., Matullo, G., Navis, G., Berglund, G., Bingham, S.A., Kooner, J.S., Connell, J.M., Bandinelli, S., Ferrucci, L., Watkins, H., Spector, T.D., Tuomilehto, J., Altshuler, D., Strachan, D.P., Laan, M., Meneton, P., Wareham, N.J., Uda, M., Jarvelin, M.R., Mooser, V., Melander, O., Loos, R.J., Elliott, P., Abecasis, G.R., Caulfield, M., and Munroe, P.B. (2009). Genome-wide association study identifies eight loci associated with blood pressure. Nat. Genet. 41, 666-676.

Pickering, G.W., Keen, H., Rose, G., and Smith, A. (1959). 
The nature of essential hypertension. Lancet 274, 1027-1030.

Pierdomenico, S.D., Di Nicola, M., Esposito, A.L., Di Mascio, R., Ballone, E., Lapenna, D., and Cuccurullo, F. Prognostic value of different indices of blood pressure variability in hypertensive patients. Am. J. Hypertens. 2009 Aug;22:842-847.

Pilia, G., Chen, W.M., Scuteri, A., Orrú, M., Albai, G., Dei, M., Lai, S., Usala, G., Lai, M., Loi, P., Mameli, C., Vacca, L., Deiana, M., Olla, N., Masala, M., Cao, A., Najjar, S.S., Terracciano, A., Nedorezov, T., Sharov, A., Zonderman, A.B., Abecasis, G.R., Costa, P., Lakatta, E., and Schlessinger, D. (2006). Heritability of cardiovascular and personality traits in 6,148 Sardinians. PLOS Genetics 2(8), e132.

Potkin, S.G., Turner, J.A., Guffanti, G., Lakatos, A., Torri, F.,
Keator, D.B., and Macciardi, F. (2009). Genome-wide strategies for discovering genetic influences on cognition and cognitive disorders: methodological considerations. Cogn. Neuropsychiatry 14, 391-418.

Purcell, S., Neale, B., Todd-Brown, K., Thomas, L., Ferreira, M.A.R., Bender, D., Maller, J., Sklar, P., de Bakker, P.I.W., Daly, M.J., and Sham, P.C. (2007). PLINK: a toolset for whole-genome association and population-based linkage analysis. Am. J. Hum. Genet. 81, 559-575..

Tobin, M.D., Raleigh, S.M., Newhouse, S., Braund, P., Bodycote, C., Ogleby, J., Cross, D., Gracey, J., Hayes, S., Smith, T., Ridge, C., Caulfield, M., Sheehan, N.A., Munroe, P.B., Burton, P.R., and Samani, N.J. (2005). Association of WNK1 gene polymorphisms and haplotypes with ambulatory blood pressure in the general population. Circulation 112, 3423-3429. 